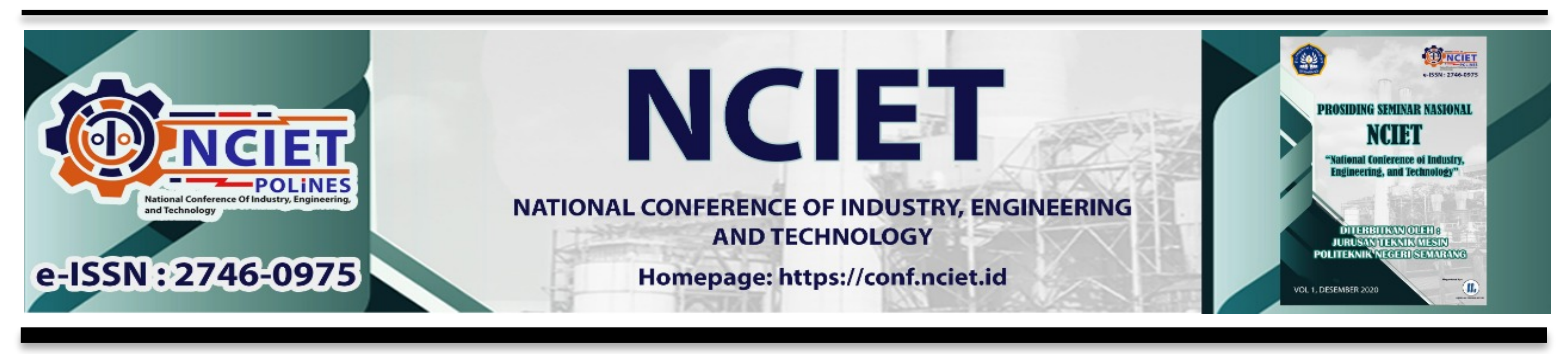

Prosiding Seminar Nasional NCIET Vol.1 (2020) B518-B527

$1^{\text {st }}$ National Conference of Industry, Engineering and Technology 2020,

Semarang, Indonesia.

\title{
RANCANG BANGUN TURBIN ANGIN SAVONIUS-DARRIEUS TIPE CEBONG
}

\section{Daniel Chandra*, Dyah Eriana Putri Maharani, Farid Banna, Nisrina Aufa Ramadhani, F.Gatot Sumarno, M. Denny Surindra}

\author{
Jurusan Teknik Mesin, Politeknik Negeri Semarang
}

J1. Prof. H. Soedarto, SH., Tembalang, Semarang, 50275

*E-mail: secretariat@polines.ac.id

\begin{abstract}
Abstrak
Tujuan penelitian ini adalah mengkaji kinerja turbin angin savonius darrieus tipe cebong dimana diberikan variasi kecepatan angin $(\mathrm{m} / \mathrm{s})$ yang digunakan untuk memutar sudu turbin yang diukur menggunakan anemometer. Tahapan penelitian ini meliputi pembuatan turbin angin savonius darrieus tipe cebong, perakitan turbin angin savonius-darreus tipe cebong, dan pengujian karakteristik kinerja turbin angin savonius darrieus tipe cebong. Hasil dari pengujian turbin angin savonius darrieus tipe cebong dengan variasi kecepatan angin $6 \mathrm{~m} / \mathrm{s}, 7 \mathrm{~m} / \mathrm{s}, 8 \mathrm{~m} / \mathrm{s}$, dan $9 \mathrm{~m} / \mathrm{s}$ diperoleh torsi tertinggi yang dihasilkan sebesar $0,924 \mathrm{Nm}$ pada putaran $45,3 \mathrm{rpm}$, pada kecepatan angin 9 $\mathrm{m} / \mathrm{s}$. Daya kinetik tertinggi yang dihasilkan sebesar 220,450 Watt pada kecepatan angin $9 \mathrm{~m} / \mathrm{s}$. Daya mekanik tertinggi yang dihasilkan sebesar 5,708 Watt pada putaran 65,7 rpm dan kecepatan angin 8 $\mathrm{m} / \mathrm{s}$. Turbin angin savonius-darrieus tipe cebong dapat berputar ketika TSR sebesar 0,063 sampai 0,723. Efisiensi maksimum terbaik yang diperoleh sebesar $4,869 \%$ pada kecepatan angin $7 \mathrm{~m} / \mathrm{s}$ dengan TSR 0,463. Turbin angin savonius-darrieus tipe cebong cocok digunakan untuk kecepatan angin menengah hingga rendah $(\leq 7 \mathrm{~m} / \mathrm{s})$.
\end{abstract}

Kata Kunci: turbin angin; kecepatan angin; efisiensi

\section{PENDAHULUAN}

Energi terbarukan merupakan cara alternatif dalam mengurangi konsumsi energi fosil yang digunakan sebagai pemabangkit listrik di Indonesia. Energi fosil merupakan energi yang tidak dapat diperbarui sehingga suatu saat akan habis. Sehingga kita tidak bisa mengandalkan energi fosil untuk pembangkit listrik. Apalagi dewasa ini, Indonesia sedang memiliki program 35.000 MW diusulkan oleh Presiden Joko Widodo yang kemudian tertuang dalam Peraturan Presiden No.4 Tahun 2016 mengenai Percepatan Pembangunan Infrastruktur Ketenagalistrikan dimana penggunaan batu bara, gas dan minyak bumi yang paling utama. Untuk meminimalisir penggunaan bahan bakar fosil, penggunaan sumber 
daya lain yang dapat diperbarui dengan jumlah yang melimpah yaitu angin. Sesuai dengan letak geografis Indonesia yang strategis, Indonesia memiliki potensi angin yang melimpah.

Angin adalah salah satu bentuk energi terbarukan yang memiliki potensi untuk menambah pasokan energy nasional. Angin global disebabkan oleh perbedaan tekanan di bumi permukaan akibat pemanasan tidak merata bumi dengan radiasi matahari dan pengaruh rotasi bumi. Turbin angin adalah sebuah alat yang memanfaatkan energi kinetik angin dan mengubahnya kedalam bentuk energi gerak putaran rotor dan poros generator untuk menghasilkan energi listrik. Energi gerak yang berasal dari angin akan diteruskan menjadi gaya gerak dan torsi pada poros generator yang kemudian akan dihasilkan energi listrik. Turbin angin poros vertikal merupakan turbin angin yang dapat digunakan untuk memanfaatkan kecepatan angin yang rendah. yang mempunyai ciri keberadaan poros tegak lurus terhadap arah aliran angin atau tegak lurus terhadap permukaan tanah. Turbin vertikal memiliki banyak kelebihan dibanding turbin horizontal antara lain yaitu :

- Tidak membutuhkan struktur menara yang besar.

- Sebuah TAPV bisa diletakkan lebih dekat ke tanah, membuat pemeliharaan bagianbagiannya yang bergerak jadi lebih mudah.

- TAPV memiliki kecepatan awal angin yang lebih rendah daripada TAPH.

Sehingga penulis melakukan penelitian dengan judul "Rancang Bangun Turbin Angin Savonius-Darrieus Tipe Cebong”. Adapun tujuan dari penelitian ini yaitu :

1. Membuat turbin angin savonius-darrieus tipe cebong.

2. Melakukan uji kinerja model turbin savonius-darrieus tipe cebong.

3. Melakukan analisis kinerja turbin angin savonius-darrieus tipe cebong.

\section{TINJAUAN PUSTAKA}

Angin adalah udara yang bergerak dari tekanan udara yang lebih tinggi ke tekanan udara yang lebih rendah. Perbedaan tekanan udara disebabkan oleh perbedaan suhu udara akibat pemanasan atmosfir yang tidak merata oleh sinar matahari. Karena bergerak angin memiliki energi kinetik. Energi angin dapat dikonversi atau ditransfer ke dalam bentuk energi lain seperti listrik atau mekanik dengan menggunakan kincir atau turbin angin. Oleh karena itu, kincir atau turbin angin sering disebut sebagai Sistem Konversi Energi Angin (SKEA).

Turbin angin adalah sebuah alat yang memanfaatkan energi kinetik angin dan mengubahnya kedalam bentuk energi gerak putaran rotor dan poros generator untuk 
menghasilkan energi listrik. Energi gerak yang berasal dari angin akan diteruskan menjadi gaya gerak dan torsi pada poros generator yang kemudian akan dihasilkan energi listrik. Berdasarkan arah sumbu geraknya, turbin angin terbagi menjadi 2, yaitu: turbin angin sumbu horizontal dan turbin angin sumbu vertikal:

1. Turbin Angin Poros Vertikal

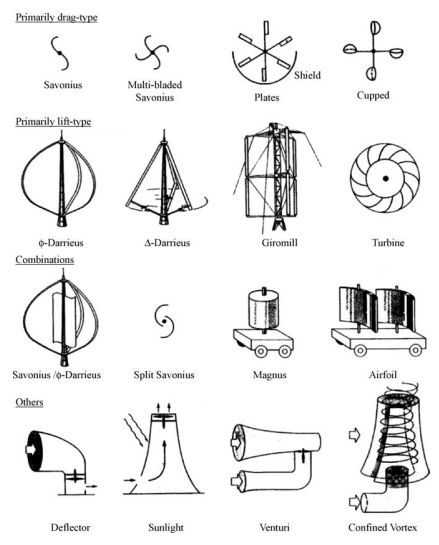

Gambar 1. Jenis Turbin Poros Vertikal

2. Turbin Angin Poros Horizontal

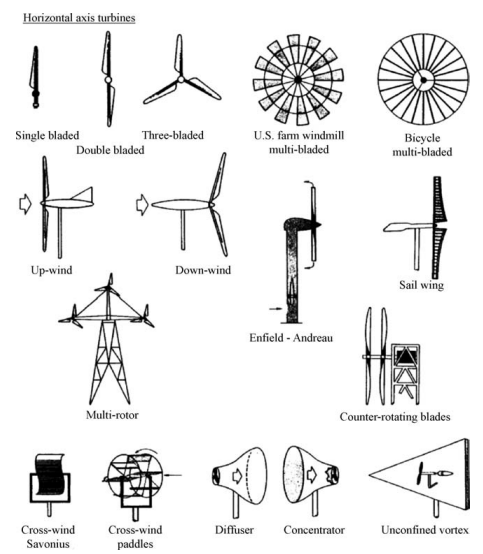

Gambar 2. Jenis turbin poros horizontal

Untuk mengetahui kinerja dari turbin angin tipe Savonius, dapat digunakan rumus-rumus sebagai berikut :

\section{Daya Kinetik (Pkin)}

Daya kinetic adalah energi angin yang secara efektif diterima oleh turbin.

$$
\mathrm{P}_{\text {kin }}=0,5 \rho \mathrm{A} \mathrm{v}^{3}
$$

Keterangan :

$\mathrm{P}_{\text {kin }}=$ Daya Kinetik Angin $($ Watt $)$

$\mathrm{v} \quad=$ kecepatan $\operatorname{angin}(\mathrm{m} /$ detik $)$ 
$\rho \quad=$ Massa jenis udara $\left(\mathrm{kg} / \mathrm{m}^{3}\right)$

A $=$ Area penangkapan angin $\left(\mathrm{m}^{2}\right)$

\section{Daya Mekanik (Pmek)}

Daya mekanik adalah daya putaran poros yang dihasilkan oleh sudu (blade) turbin.

$$
\mathrm{P}_{\mathrm{mek}}=\frac{2 \pi n \tau}{60}
$$

Keterangan :

$\mathrm{P}_{\text {mek }}=$ daya mekanik $($ Watt $)$

$\mathrm{n}=$ putaran turbin (rpm)

$\tau=$ torsi $(\mathrm{Nm})$.

\section{TSR (Tip Speed Ratio)}

TSR adalah perbandingan antara kecepatan ujung blade dengan kecepatan angin bebas, yaitu:

$$
\mathrm{TSR}=\frac{(\pi D n) / 60}{v}
$$

Keterangan :

TSR $=$ Tip Speed Ratio,

$\mathrm{D}=$ diameter lengan sudu $(\mathrm{m})$

$\mathrm{n}=$ putaran turbin (rpm)

$\mathrm{v}=$ kecepatan angin tanpa hambatan $(\mathrm{m} / \mathrm{s})$

\section{Torsi}

Torsi merupakan hasil perkalian dari gaya dengan jarak.

$$
\tau=(m 2-m 1) g
$$

Keterangan :

$\tau=$ Torsi $(\mathrm{Nm})$

$\mathrm{F}=$ Gaya yang dihasilkan $\left(\mathrm{kgm} / \mathrm{s}^{2}\right)$

M1 = massa pada beban $(\mathrm{kg})$

M2 = massa yang dihasilkan pada neraca $(\mathrm{kg})$

$\mathrm{r}=$ jari jari $(\mathrm{m})$

\section{Coefficient of Power}


Coefficient of Power atau koefisien daya adalah perbandingan antara daya mekanik yang dihasilkan oleh poros dengan daya yang dimiliki angin.

$$
\mathrm{Cp}=\frac{P_{\text {mek }}}{P_{\text {kin }}}
$$

\section{METODE PENELITIAN}

Secara singkat, langkah-langkah penelitian dirangkum dalam bentuk flowchart seperti Gambar 3 :

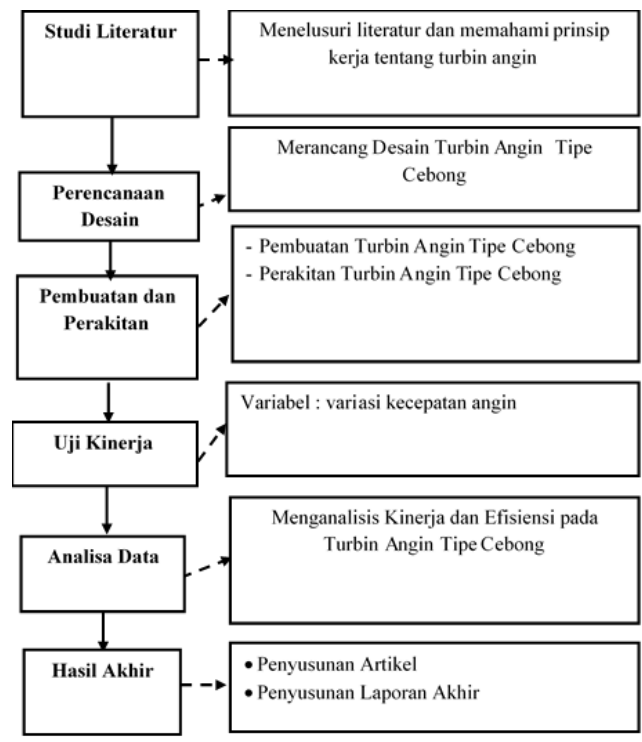

Gambar 3. Flowchart langkah penelitian

Dalam program penelitian ini metode yang digunakan adalah dengan melakukan penelusuran sumber-sumber pustaka yang terkait dengan penelitian kami, serta dengan cara melakukan pengujian terhadap turbin yang kami buat. Langkah-langkah penelitian diuraikan seperti berikut ini. Persiapan langkah ini dilakukan berdasarkan objek penelitian meliputi jurnal-jurnal dan artikel. Metode ini dilakukan dengan cara menelusuri di internet dan mempelajari buku-buku tentang turbin angin yang telah ada dari perpustakaan. Desain model turbin, setelah melakukan studi pustaka didapatkan beberapa sumber pustaka tentang model turbin. Turbin angin Savonius-Darrieus tipe cebong dibuat dari stainless steel untuk bahan savonius dengan menggunakan metode roll dan bahan plastik untuk sudu Darrieus dengan menggunakan metode $3 \mathrm{~d}$ printing. Tinggi sudu turbin tersebut sebesar $700 \mathrm{~mm}$. Pada penelitian ini terdapat variasi kecepatan angin yaitu $4 \mathrm{~m} / \mathrm{s}, 5 \mathrm{~m} / \mathrm{s}, 6 \mathrm{~m} / \mathrm{s}, 7 \mathrm{~m} / \mathrm{s}, 8 \mathrm{~m} / \mathrm{s}$ dan 9 $\mathrm{m} / \mathrm{s}$. Pengambilan data dibantu dengan menggunakan beberapa alat yaitu blower, tachometer untuk mengukur putaran poros, anemometer untuk mengukur kecepatan angin dan neraca untuk mengukur gaya yang dihasilkan poros. Setelah semua pengujian selesai 
maka didapat data hasil kinerja dari turbin dan selanjutnya dapat dibuat grafik karakteristik kinerja dari turbin tersebut. Melakukan pengolahan data ditunjukan dalam bentuk tabel dan kurva karakteristik kinerja turbin angin. Tahapan terakhir menyimpulkan hasil penelitian, menyusun laporan akhir dan artikel ilmiah.

Langkah penelitian :

1. Menyiapkan alat dan bahan yang diperlukan antara lain blower, anemometer, dan tachometer.

2. Menghidupkan blower.

3. Mengatur jarak blower dengan turbin untuk mendapatkan kecepatan angin tertentu yang diukur dengan anemometer.

4. Mengukur kecepatan angin yang berada di depan turbin.

5. Mengatur kecepatan angin di semua sisi turbin biar seimbang.

6. Mengukur putaran yang dihasilkan dengan tachometer.

7. Mencatat hasil dari putaran, kecepatan angin di depan sudu.

8. Melakukan langkah yang sama dari langkah 4 sampai langkah 7 untuk variasi kecepatan angin.

9. Merapikan peralatan setelah selesai pengujian.

10. Mengolah data, mencatat hasil dalam tabel dan membuat grafik.

\section{HASIL DAN PEMBAHASAN}

Berikut ini merupakan hasil model dari turbin angin savonius-darrieus tipe cebong dapat dilihat pada Gambar 4.

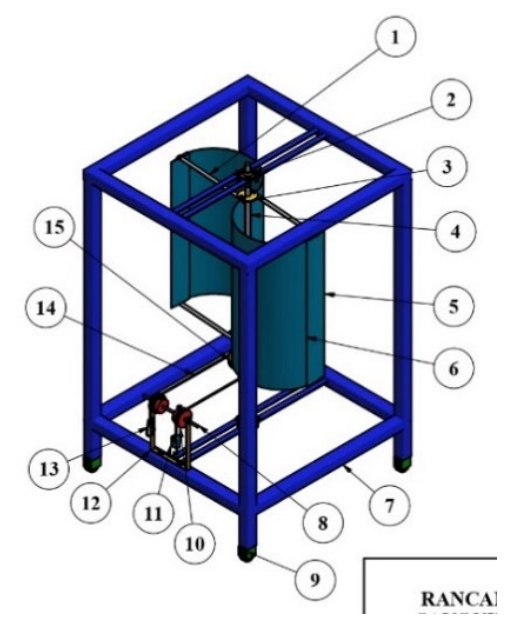

Gambar 4. Model Turbin Angin savonius - darrieus tipe cebong 
Setelah pengujian turbin angin savonius-darrieus tipe cebong tersebut menghasilkan parameter - parameter yang diperlukan maka dilakukan analisa sebagai berikut :

\section{Grafik Hubungan Torsi Terhadap Putaran}

Pada grafik karakteristik torsi terhadap putaran seperti pada gambar 5 diperoleh data torsi yang selalu naik ketika diberikan beban yang lebih tinggi.

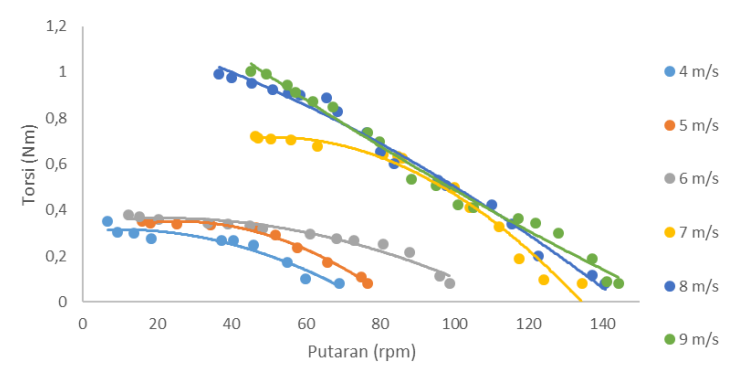

Gambar 5. Karakteristik Torsi terhadap putaran

Pada kecepatan angin $4 \mathrm{~m} / \mathrm{s}$ torsi maksimum yang dihasilkan sebesar 0,35 Nm. Kemudian kecepatan angin $5 \mathrm{~m} / \mathrm{s}$ torsi maksimum yang dihasilkan sebesar $0,35 \mathrm{Nm}$. Untuk kecepatan angin $6 \mathrm{~m} / \mathrm{s}$ torsi maksimum yang dihasilkan sebesar 0,38 Nm. Pada kecepatan angin $7 \mathrm{~m} / \mathrm{s}$ torsi maksimum yang dihasilkan sebesar $0,722 \mathrm{Nm}$. Kemudian kecepatan angin $8 \mathrm{~m} / \mathrm{s}$ torsi maksimum yang dihasilkan sebesar $0,991 \mathrm{Nm}$. Untuk kecepatan angin $9 \mathrm{~m} / \mathrm{s}$ torsi maksimum yang dihasilkan sebesar 1,005 Nm. Sehingga dapat disimpulkan bahwa torsi maksimum yang dihasilkan turbin yaitu sebesar 1,005 pada kecepatan angin $9 \mathrm{~m} / \mathrm{s}$. Semakin tinggi putaran maka semakin kecil nilai Torsi. Dari grafik tersebut juga dapat disimpulkan bahwa semakin besar kecepatan angin maka torsi yang dihasilkan juga akan semakin besar.

\section{Grafik Hubungan Daya Mekanik Terhadap Putaran}

Pada grafik karakteristik daya mekanik terhadap putaran seperti pada gambar 6 dapat diketahui bahwa pada kecepatan angin $4 \mathrm{~m} / \mathrm{s}$ daya mekanik maksimum yang dihasilkan sebesar 1,242 Watt. 


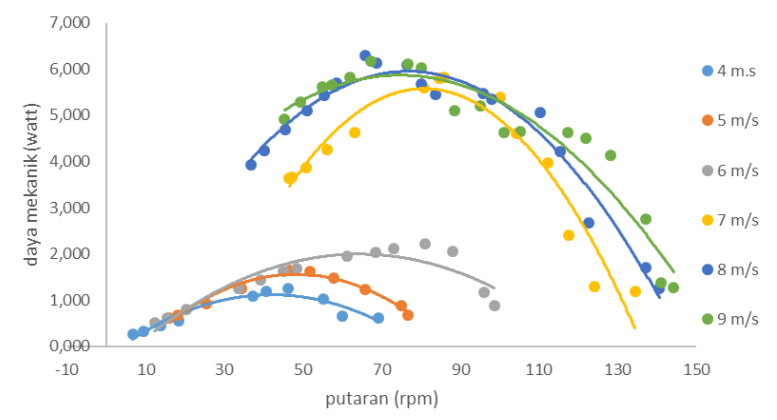

Gambar 6. Karakteristik daya mekanik terhadap putaran

Kemudian dari Gambar 6 juga dapat diketahui kecepatan angin $5 \mathrm{~m} / \mathrm{s}$ torsi maksimum yang dihasilkan sebesar 1,634 Watt. Untuk kecepatan angin $6 \mathrm{~m} / \mathrm{s}$ torsi maksimum yang dihasilkan sebesar 2,215 Watt. Pada kecepatan angin $7 \mathrm{~m} / \mathrm{s}$ torsi maksimum yang dihasilkan sebesar 5,811 Watt. Kemudian kecepatan angin $8 \mathrm{~m} / \mathrm{s}$ torsi maksimum yang dihasilkan sebesar 6,289 Watt. Untuk kecepatan angin $9 \mathrm{~m} / \mathrm{s}$ torsi maksimum yang dihasilkan sebesar 6,171 Watt. Sehingga dapat disimpulkan bahwa torsi maksimum yang dihasilkan turbin yaitu sebesar 6,171 Watt pada kecepatan angin $8 \mathrm{~m} / \mathrm{s}$. Dari grafik tersebut juga dapat disimpulkan semakin tinggi putaran akan semakin tinggi daya mekanik yang dihasilkan. Ketika telah mencapai daya mekanik maksimum maka ketika bertambahnya putaran akan membuat daya mekanik yang dihasilkan semakin kecil. Dan juga dapat disimpulkan bahwa semakin besar kecepatan angin maka daya mekanik juga akan semakin besar.

\section{Grafik Hubungan Cp Terhadap Putaran}

Pada grafik karakteristik Cp terhadap putaran seperti pada gambar 7 diketahui bahwa pada kecepatan angin $4 \mathrm{~m} / \mathrm{s}$ Cp maksimum yang dihasilkan sebesar 6,419 \% pada putaran 46,1 rpm.

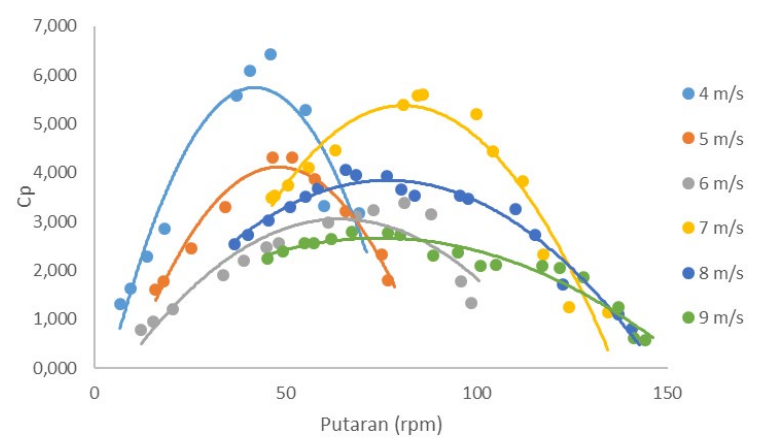

Gambar 7. Karakteristik Cp terhadap putaran 
Kemudian kecepatan angin $5 \mathrm{~m} / \mathrm{s}$ Cp maksimum yang dihasilkan sebesar 4,323\% pada putaran 46,7 rpm. Untuk kecepatan angin $6 \mathrm{~m} / \mathrm{s}$ Cp maksimum yang dihasilkan sebesar 3,392 $\%$ pada putaran 81 rom. Pada kecepatan angin $7 \mathrm{~m} / \mathrm{s} \mathrm{Cp}$ maksimum yang dihasilkan sebesar $5,602 \%$ pada putaran $86 \mathrm{rpm}$. Kemudian kecepatan angin $8 \mathrm{~m} / \mathrm{s} \mathrm{Cp}$ maksimum yang dihasilkan sebesar 4,062 \% pada 65,7 rpm. Untuk kecepatan angin $9 \mathrm{~m} / \mathrm{s}$ torsi maksimum yang dihasilkan sebesar 2,799 \% pada putaran 67,3 rpm. Sehingga dapat disimpulkan bahwa Cp maksimum yang dihasilkan turbin yaitu sebesar 6,419 pada kecepatan angin $4 \mathrm{~m} / \mathrm{s}$. Dari grafik tersebut juga dapat disimpulkan semakin tinggi putaran akan semakin tinggi Cp yang dihasilkan. Ketika telah mencapai Cp maksimum maka ketika bertambahnya putaran akan membuat Cp yang dihasilkan semakin kecil.

\section{Grafik Hubungan Cp Terhadap TSR}

Pada grafik karakteristik Cp terhadap TSR seperti pada gambar 8 diketahui bahwa pada kecepatan angin $4 \mathrm{~m} / \mathrm{s} \mathrm{Cp}$ maksimum yang dihasilkan sebesar 6,419\%.

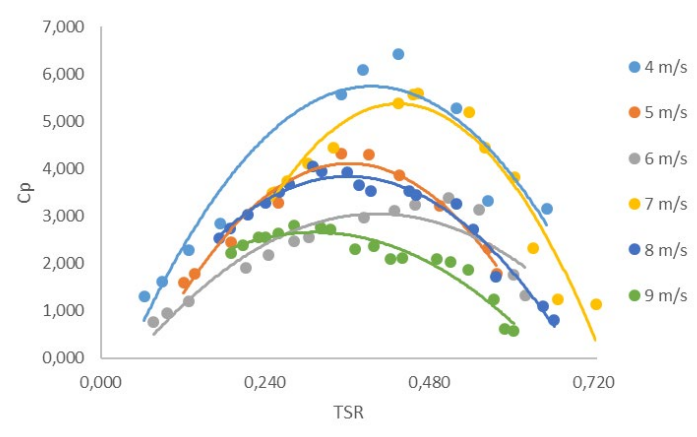

Gambar 8. Karakteristik Cp terhadap TSR

Kemudian kecepatan angin $5 \mathrm{~m} / \mathrm{s}$ torsi maksimum yang dihasilkan sebesar 4,323\%. Untuk kecepatan angin $6 \mathrm{~m} / \mathrm{s}$ torsi maksimum yang dihasilkan sebesar 3,392\%. Pada kecepatan angin $7 \mathrm{~m} / \mathrm{s}$ torsi maksimum yang dihasilkan sebesar 5,602\%. Kemudian kecepatan angin 8 $\mathrm{m} / \mathrm{s}$ torsi maksimum yang dihasilkan sebesar 4,062 \%. Untuk kecepatan angin $9 \mathrm{~m} / \mathrm{s}$ torsi maksimum yang dihasilkan sebesar 2,799 \%. Sehingga dapat disimpulkan bahwa Cp maksimum yang dihasilkan turbin yaitu sebesar 6,419 pada kecepatan angin $4 \mathrm{~m} / \mathrm{s}$. Dari grafik tersebut juga dapat disimpulkan semakin tinggi TSR akan semakin tinggi Cp yang dihasilkan. Ketika telah mencapai Cp maksimum maka ketika bertambahnya TSR akan membuat Cp yang dihasilkan semakin kecil. Cp turbin terbaik yaitu pada kecepatan $4 \mathrm{~m} / \mathrm{s}$, kemudian diikuti pada kecepatan angin $7 \mathrm{~m} / \mathrm{s}, 5 \mathrm{~m} / \mathrm{s}, 8 \mathrm{~m} / \mathrm{s}, 6 \mathrm{~m} / \mathrm{s}$ dan $9 \mathrm{~m} / \mathrm{s}$. 


\section{KESIMPULAN}

Daya mekanik maksimum yang dihasilkan turbin angin savonius-darrieus tipe cebong yaitu sebesar 6,289 watt pada variasi beban rem 2,5 kg dengan kecepatan $8 \mathrm{~m} / \mathrm{s}$. Coefficientc of power tertinggi pada pengujian turbin angin savonius-darrieus tipe cebong yaitu sebesar $6,419 \%$ dengan nilai tip speed ratio (TSR) sebesar 0,434 yang diperoleh pada saat kecepatan angin $4 \mathrm{~m} / \mathrm{s}$ dan variasi beban rem $0,5 \mathrm{~kg}$. Berdasarkan grafik hubungan TSR dan Cp, grafik hubungan antara daya mekanik dan Cp maka dapat diketahui bahwa turbin angin savoniusdarrieus tipe cebong memiliki kerja paling baik ketika kecepatan angin $4 \mathrm{~m} / \mathrm{s}$. Penambahan sudu darrieus pada turbin savonius berpengaruh karena pada kecepatan angin $7 \mathrm{~m} / \mathrm{s}$ turbin ini masih dapat menghasilkan kinerja yang baik.

\section{DAFTAR PUSTAKA}

Balineni, S.C., Krisnha, S.R., Kumar, B.S., Kumar, G.V., 2011, Design and Fabrication of Savonius Vertical Axis Wind Turbin, Department of Mechanical Engineering Gokaraju Rangaraju Institute of Engineering and Technology, Jawaharlal Nehru Technological University.

E.H. Lysen, 1983. Introduction to Wind Energy. Consultancy Services: Wind Energy for Developing Countries: Amersfoort, Netherlands.

Hau, Erich. 2006. Wind Turbines Fundamentals, Technologies, Application, Economics. Edisi Kedua. Germany. Springer

Manwell J.F., MCGowan J.G., Rogers A.L. 2002. Wind Energy Explaine: Theory Design and Application. University of Massachusetts : John \& Willey Ltd

Prananto, Haryo Dwi. 2014. Rancang Bangun Turbin Angin Vertikal Tipe Hybrid SavoniusDarrieus Dengan Perbedaan Jumlah Sudu, Fakultas Matematika dan Ilmu Pengetahuan Alam, Universitas Negeri Jakarta : Jakarta

Pudjanarso, Astu dan Djati Nursahud. 2015. Mesin Konversi Energi Edisi 3. Yogyakarta : C.V Andi Offset

Sarjito. 2010. Studi Karakteristik Airfoil NACA 2410 Dan NACA 0012 Pada Berbagai Variasi Angle Of Attack. Media Teknik Mesin : Surakarta.

Soelaiman. 2006. Pengaruh bentuk Sudu Terhadap Unjuk Kerja Turbin Angin Savonius : Cepu.

Sularso. 1994. Dasar Perencanaan dan Pemilihan Elemen Mesin. Pradnya Pramita : Jakarta.

Y., Daryanto. 2007. Kajian Potensi Angin Untuk Pembangkit Listrik Tenaga Bayu. Yogyakarta 